\title{
Elastic Response of Cross-Laminated Timber Panels using Finite Element and Analytical Techniques
}

DOI:

10.1139/cjce-2020-0205

\section{Document Version}

Accepted author manuscript

Link to publication record in Manchester Research Explorer

\section{Citation for published version (APA):}

Albostami, A., Wu, Z., \& Cunningham, L. (2020). Elastic Response of Cross-Laminated Timber Panels using Finite Element and Analytical Techniques. Canadian Journal of Civil Engineering. https://doi.org/10.1139/cjce-2020-0205

\section{Published in:}

Canadian Journal of Civil Engineering

\section{Citing this paper}

Please note that where the full-text provided on Manchester Research Explorer is the Author Accepted Manuscript or Proof version this may differ from the final Published version. If citing, it is advised that you check and use the publisher's definitive version.

\section{General rights}

Copyright and moral rights for the publications made accessible in the Research Explorer are retained by the authors and/or other copyright owners and it is a condition of accessing publications that users recognise and abide by the legal requirements associated with these rights.

\section{Takedown policy}

If you believe that this document breaches copyright please refer to the University of Manchester's Takedown Procedures [http://man.ac.uk/04Y6Bo] or contact uml.scholarlycommunications@manchester.ac.uk providing relevant details, so we can investigate your claim.

\section{OPEN ACCESS}




\title{
Elastic Response of Cross-Laminated Timber Panels using Finite Element and Analytical Techniques
}

\author{
Asad S. Albostami ${ }^{1 *}$, Zhangjian $\mathrm{Wu}^{2}$, Lee S. Cunningham ${ }^{2}$ \\ ${ }^{1}$ School of Civil Engineering, University of Petra, Amman-Jordan. \\ ${ }^{2}$ School of Mechanical, Aerospace and Civil Engineering, The University of Manchester, \\ Manchester M13 9PL, UK
}

*Corresponding author:

Asad S. Albostami

00962791102786

E-mail address: asad.albostami@uop.edu.jo

Word Count: 5547 


\begin{abstract}
Cross-Laminated Timber (CLT) is an engineered timber composite that is finding increasing structural application in construction today. Analysis of the structural behavior of CLT can be carried out by various analytical and numerical methods. Due to the complex behavior of CLT, use of numerical modelling such as the Finite Element Method (FEM) offers a convenient approach to analysis. In this paper, simulation of the elastic behavior of 1-way and 2-way spanning CLT panels using the FEM program ABAQUS is presented. Various modelling choices are explored numerically with the results being evaluated against those from either a 3D analytical method known as the State Space Approach (SSA) or existing experimental data. Among the case studies examined is a novel boundary condition for the SSA solution. In general, the optimum finite element model produced reasonable levels of accuracy with an average relative error equal to $3 \%$ in comparison to the SSA and a maximum of $10 \%$ in comparison to the experimental results.
\end{abstract}

\title{
Keywords
}

Cross-laminated timber, Finite element method, Analytical solution, State space approach. 


\section{Cross-Laminated Timber (CLT): Background and Characteristics}

CLT is a laminated timber composite which can be used to form structural elements including walls, floor plates and roofs etc. It was first developed in Switzerland and Austria in the mid1990s [1].

CLT panels are formed from at least three plies of wooden boards orthogonally cross-stacked and glued together on their faces, typically in a symmetric lay-up. Given that alternate plies are placed with the grain direction at $90^{\circ}$ to that of the ply below, CLT can be considered as an orthotropic composite panel [2].

CLT panels can be produced in large sizes with comparable thickness to masonry or concrete walls. Consequently, CLT panels have significant strength and have allowed timber to compete with concrete and steel in multi-storey applications e.g. CLT buildings of 9 storeys or more have been constructed to date [3].

The use of CLT panels has increased in the construction sector over the last 10 years due to the significant advantages they offer [4], these include CLT's high strength to weight ratio, ease of handling, quick erection time and good thermal and sound insulation. Typical practical dimensions of a CLT panel [4] are shown in Fig. 1. In addition to the aforementioned, interest in the use of CLT has increased due to today's demand for more sustainable construction forms [5].

CLT panels can be subject to in-plane and out-plane forces. In the case of CLT floor panels, these typically span one-way due to practical constraints on panel widths ( $\sim 3 \mathrm{~m}$ max.) and floor spans. For transverse spans greater than 3m, 2-way action is theoretically possible with moment transfer connection details. Commonly in the case of CLT wall panels, where storey 
heights are limited to $3 \mathrm{~m}$, 2-way action under horizontal loads is generated as the wall spans vertically between floor plates and return walls.

Due to the relatively low Young's modulus of timber in comparison to other construction materials, deflection of CLT panels often governs their design. Given the layered composite nature of the CLT panel, obtaining an accurate section stiffness can be challenging with various methods in common use. Shear deformation due to the flexible bond between timber plies influences the stress distribution and stiffness of the CLT panel. In CLT design, the phenomenon of rolling shear, whereby a longitudinal shear plane develops at the interface between plies, is often critical in determining panel strength [1]. The rolling shear strength and modulus depend on many factors such as the dimensions of the CLT boards and timber species etc. Different models have been developed to quantify the rolling shear modulus; however, no single specific method has been universally adopted. Typically, the rolling shear modulus is taken to be $1 / 10$ of the shear modulus of the CLT board parallel to the grain [4].

\subsection{Existing numerical modelling of CLT}

For designers, a number of analytical approaches are commonly used for CLT including mechanically jointed beam theory (gamma method), composite theory (the k-method) and the shear analogy method as outlined in [4]. Crucially, the accuracy of each of these methods tends to reduce as the span to depth ratio of the CLT panel decreases beyond a threshold of 15 [6].

As an alternative to the aforementioned analytical models, researchers have studied the complex behavior of CLT by using numerical methods, primarily the Finite Element Method (FEM).

In 2015, Shahnewaz et al. [7] validated a numerical model using the experimental data from CLT beam and wall tests published in the Canadian CLT Handbook [4]. The FEM model was 
developed using the software ANSYS. The bond between plies in the panel was modelled using contact elements and a high frictional coefficient based on the high stiffness of the glue. The FEM model gave results with $\sim 10 \%$ difference to the experimental data in predicting elastic stiffness of the CLT. Using the validated model, a parametric study was conducted to explore the effect of thickness on the in-plane stiffness of CLT panels. [7] found that when the thickness of the panels is doubled, the stiffness is increased by up to $24 \%$. Serrano and Enquist [8] simulated a series of experiments on a square three-ply CLT panel subject to uniform compressive stress on the top surface. For the FEM model, [8] recommended that the interaction between the individual boards be taken into account for more accurate results. [8] also found that at low load levels, large strains have already been developed at the interface between the plies of the CLT. Therefore, in order to fully capture the post-peak behavior observed in the test, an orthotropic plastic material model was suggested. However, it should be noted that from a design point of view, only the elastic behavior of a timber member is considered [4 \& 9].

Vilguts et al. [10] simulated via ANSYS an experiment of 1-way spanning CLT panels with a total thickness of $95 \mathrm{~mm}$ under distributed load. Vilguts et al. compared the numerical and experimental stresses acting on the edge of the panel and the maximum vertical displacement. The model and experimental results showed a relatively good match with deviations not exceeding $\pm 20 \%$.

To gain an improved understanding of the behavior of CLT panels including shear failure, five-ply and seven-ply CLT panels under concentrated loads were studied by Bogensperger and Jöbstl [11]. Different parameters known to have an effect on the shear behavior such as the span to thickness ratio were investigated numerically. The non-linear analysis was carried out using FEM. For simplification in their model, all the stresses in the interactions between 
the layers were neglected. It was found that the agreement between the experiment and the FEM results was good with approximate differences less than $20 \%$ in the linear elastic response, (with the FEM model predicting a stiffer response), but for the non-linear stage, the mechanical strength was overestimated by a greater margin. The results were improved after softening of the material was added in the model. In the same way, Saavedra Flores et al. [12] investigated the mechanical behavior of CLT panels by FEM within a multi-scale model. [12] validated their models against a series of experimental tests for bending, in-plane shear and axial stiffness properties. The numerical models gave good agreement compared with the experimental data; with a relative error of around $11 \%$.

In the present paper, FEM will be used to investigate the elastic behavior of CLT panels and the results will be compared with a 3D analytical approach known as the State Space Approach (SSA) [13]. The SSA has been previously shown by the authors to be capable of capturing the elastic behavior of CLT to a good level of accuracy in comparison to experimental results [14]. The SSA originates from the linear control system where the principal concern is the relationship between inputs (or source) and outputs (or responses) [15]. The SSA provides theoretically accurate three-dimensional solutions that guarantee continuous transverse stress distributions across the thickness of the panels while the boundary conditions and the continuity at the interfaces are satisfied. Importantly, the SSA can give the full range of elastic structural behavior with theoretical accuracy for various plate thicknesses from thin to very thick panels [16], unlike the previously mentioned standard analytical approaches. The governing equations behind the SSA are briefly outlined section 1.2 , further details can be found in reference [15].

For designers, accurate methods of capturing the elastic behavior of CLT is key to achieving structural efficiency. Due to the composite nature of a CLT panel and typical span to depth 
ratios in practice, many standard analytical approaches are either not applicable or have reduced accuracy, hence the appeal of finite element techniques along with more sophisticated analytical techniques such as the SSA. The current paper is novel in its comparison of different finite element approaches to modelling CLT elastic behavior. Similarly, the analytical solution of a plate with three sides simply-supported and one free edge, has been hitherto unexplored using the SSA. The novel derivation of the SSA formulation for this boundary condition is the subject of a forthcoming publication by the authors.

\subsection{Overview of the SSA formulation}

Considering a rectangular plate with the boundary conditions of four sides simply-supported as shown in Fig. 2, this boundary condition can be satisfied by solving Eq. (1). To solve this equation, let $\zeta=m \pi / a$ and $\eta=n \pi / b$, where $m$ and $n$ are the numbers of Fourier series terms of the analytical solution in the $x$ and $y$ directions, respectively.

$$
\frac{\partial}{\partial z}\left\{\mathrm{~F}_{m n}(z)\right\}=\left[\mathrm{D}_{m n}\right]\left\{\mathrm{F}_{m n}(z)\right\}
$$

$\left\{\mathrm{F}_{m n}(z)\right\}=\left[U_{m n}(z) V_{m n}(z) Z_{m n}(z) X_{m n}(z) Y_{m n}(z) W_{m n}(z)\right]^{\mathrm{T}}$ is the state vector of the plate with the number of Fourier series terms $m-n^{\text {th }}$ and the system matrix is

$$
\left[\mathrm{D}_{m n}\right]=\left[\begin{array}{cccccc}
0 & 0 & 0 & C_{8} & 0 & -\zeta \\
0 & 0 & 0 & 0 & C_{9} & -\eta \\
0 & 0 & 0 & \zeta & \eta & 0 \\
C_{2} \zeta^{2}+C_{6} \eta^{2} & \left(C_{3}+C_{6}\right) \zeta \eta & C_{1} \zeta & 0 & 0 & 0 \\
\left(C_{3}+C_{6}\right) \zeta \eta & C_{6} \zeta^{2}+C_{4} \eta^{2} & C_{5} \eta & 0 & 0 & 0 \\
-C_{1} \zeta & -C_{5} \eta & C_{7} & 0 & 0 & 0
\end{array}\right]
$$

By solving the differential Eq. (1) based on the classical solution method for a linear differential equation [17], the solution can be found as:

$$
\left\{\mathrm{F}_{m n}(z)\right\}=\left[\mathrm{G}_{m n}(z)\right]\left\{\mathrm{F}_{m n}(0)\right\}
$$

Where $\left[\mathrm{G}_{m n}(z)\right]=\exp \left\{\left[\mathrm{D}_{m n}\right] . z\right\}$, and when $z=h,\left\{\mathrm{~F}_{m n}(h)\right\}=\left[\mathrm{G}_{m n}(h)\right]\left\{\mathrm{F}_{m n}(0)\right\}$ 


$$
\begin{array}{lll}
C_{1}=-\frac{C_{13}}{C_{33}} & C_{2}=C_{11}-\frac{C_{13}^{2}}{C_{33}} & C_{3}=C_{12}-\frac{C_{13} C_{23}}{C_{33}} \\
C_{4}=C_{22}-\frac{C_{23}^{2}}{C_{33}} & C_{5}=-\frac{C_{23}}{C_{33}} & C_{6}=C_{66} \\
C_{7}=\frac{1}{C_{33}} & C_{8}=\frac{1}{C_{55}} & C_{9}=\frac{1}{C_{44}}
\end{array}
$$

$C_{i j}(i, j=1,2, \ldots 6)$ is the elastic stiffness matrix of the orthotropic material of the plate. $\left\{\mathrm{F}_{m n}(0)\right\}$ and $\left\{\mathrm{F}_{m n}(h)\right\}$ are the values of the state variables on the top $(z=0)$ and bottom $(z=h)$ surfaces and can be determined uniquely on the basis of the load conditions on the top and bottom surfaces. For example, if the plate is subjected to an arbitrarily distributed external transverse pressure $q(x, y)$ on the top surface only, the state vectors on the top and bottom surfaces of the plate can be expanded into a Fourier series as shown in Eqs. (6) and (7),

and

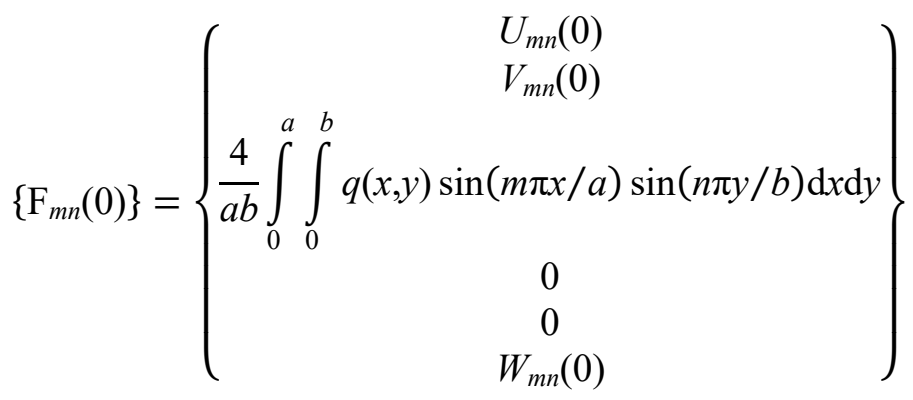

$$
\left\{\mathrm{F}_{m n}(h)\right\}^{T}=\left[\begin{array}{llllll}
U_{m n}(h) & V_{m n}(h) & 0 & 0 & 0 & W_{m n}(h)
\end{array}\right]
$$

Substituting Eqs. (6) and (7) into (3), all displacement components on the top and the bottom surfaces of the plate can be obtained, that is, $U_{m n}(0), V_{m n}(0), W_{m n}(0)$ and $U_{m n}(h), V_{m n}(h), W_{m n}(h)$.

After finding all the displacements and the transverse stresses, the three in-plane stresses can be found by using the following equation: 


$$
\left\{\begin{array}{l}
\sigma_{x} \\
\sigma_{y} \\
\tau_{x y}
\end{array}\right\}=\left[\begin{array}{cccccc}
-C_{2} \zeta & -C_{3} \eta & -C_{1} & 0 & 0 & 0 \\
-C_{3} \zeta & -C_{4} \eta & -C_{5} & 0 & 0 & 0 \\
C_{6} \eta & C_{6} \zeta & 0 & 0 & 0 & 0
\end{array}\right]\left\{\begin{array}{c}
u \\
v \\
\sigma_{z} \\
\tau_{x z} \\
\tau_{y z} \\
w
\end{array}\right\}
$$

Further simplification can be made if $q(x, y)=q$ is a constant.

\subsection{Modelling of adhesive bonding}

In CLT panels, adhesive is required to bond each successive ply, while the boards making up each ply may also have adhesive bonds along their edges.

In this paper, the adhesive between the plies will be simulated in the subsequent finite element models while the adhesive between the boards will be assumed as perfectly bonded for numerical expediency. The full bond assumption between the edges of the ply is a simplification, in practice, it is common for the edge of the boards to be left without adhesive. In the SSA, a full bond is assumed between successive plies and the boards making up the plies.

\section{FEM model of CLT panels}

In this section, five different case studies will be explored using ABAQUS. The first two studies are 3-ply CLT panels with simply-supported sides under sinusoidal (see Fig. 3) and uniformly distributed loading. The choice of mesh size and element type adopted for the FEM analysis is justified firstly. For the third and fourth case studies, the same types of loading are used but the boundary conditions have been changed to three simply-supported sides and a free edge. The numerical results for the four case studies are compared to those from the SSA. In the fifth case study, the developed FEM model will be used to simulate the behavior of a 5ply CLT beam originally tested experimentally by O'Dowd et al. [18]. 


\subsection{Case study 1: FEM model of 3-ply CLT panels with Simply-Supported sides under Sinusoidal Load}

The focused panel has the same geometry as that examined analytically by Sturzenbecher and Hofstetter [19]. The panel is symmetrical with three plies of alternate grain orientation, i.e. $[0 / 90 / 0]^{\circ}$ as shown in Fig. 3.

Each board or ply has a thickness of $30 \mathrm{~mm}$ so that the total panel thickness is $90 \mathrm{~mm}$. The in-plane dimensions of the panel are $a=b$ and $h / a=0.25$. Here $a$ is the length of the panel along the $x$-axis, $b$ is the dimension of the panel along $y$-axis and $h$ is the total thickness of the panel (z-axis) as shown in Fig. 3.

The set of elastic material parameters used for the timber plies are the same as per [19]; $E_{1}=$ $11000 \mathrm{MPa}, E_{2}=E_{3}=370 \mathrm{MPa}, G_{12}=G_{13}=690 \mathrm{MPa} ; G_{23}=50 \mathrm{MPa}, v_{12}=v_{13}=0.44$ and $v_{23}=$ 0.64. All the calculations are based on C24-grade timber as the constituent of the CLT boards, in accordance with BS EN 338 [20], these were the same properties adopted in the analytical solution by [19].

The panel is simply-supported on all sides and subject to a sinusoidal load with a maximum magnitude of $1 \mathrm{MPa}\left(q(x, y)=q_{0} \sin (\pi x / a) \sin (\pi y / b)\right.$ where $\left.q_{0}=1 \mathrm{MPa}\right)$ in the center of the top surface as shown in Fig. 3.

For the bond connection between different plies, there are a number of approaches to define layer contact, three of which are explored here. The first approach is the composite fully bonded model. The second approach is to define the contacted layers as a cohesive element and the third approach is to define the connection as an interaction contact layer. Before applying these approaches, mesh sensitivity, influence of element type and the boundary condition idealization options will be explored. 


\subsubsection{Mesh sensitivity study}

A mesh sensitivity study was undertaken to define the most appropriate for analysis. Three mesh sizes with cohesive elements between the CLT plies were investigated comprising of equal-sided elements with dimensions of 3, 6, 12 and $24 \mathrm{~mm}$. As shown in Fig. 4, when the mesh density increases, the values of the in-plane stress $\sigma_{x}$ with respect to the theoretical solution (derived from the SSA) will be more accurate. Since the difference in results between the $3 \mathrm{~mm}$ and $6 \mathrm{~mm}$ mesh size is small, the $6 \mathrm{~mm}$ mesh will be chosen for computational efficiency (the run time for the $3 \mathrm{~mm}$ mesh was $11880 \mathrm{~s}, \sim 10$ times that of the $6 \mathrm{~mm}$ mesh).

\subsubsection{Choice of element types}

As outlined in Table 1, two different solid elements have been studied (3D 8-node linear brick elements (C3D8) and 3D 20-node linear brick elements (C3D20)) [21] and the results from these have been compared with those from the SSA. Solid elements were used instead of shell elements because of their ability to map the displacements and stresses through the panel thickness. The most suitable solid element in terms of accuracy compared to the SSA is C3D20, hence this was adopted herein.

\subsubsection{Boundary Condition (BC) sensitivity}

Fig. 5 shows two different options to create simply-supported edges. The first BC1 is whereby $\mathrm{U} 3$ is equal to zero along all the edges. The second, $\mathrm{BC} 2$ is whereby $\mathrm{U} 2$ and $\mathrm{U} 3$ are equal to zero along the $y$-axis, and $\mathrm{U} 1$ and $\mathrm{U} 3$ are equal to zero along the $x$-axis (note $\mathrm{U}$ is a translational restraint, 1, 2, and 3 are the global $x, y$ and $z$ directions). From Table 1, BC2 is closest to the theoretical solution [22].

Fig. 6 shows $\sigma_{x}$ for $\mathrm{BC} 1$ and $\mathrm{BC} 2$ with the results of the SSA. From this figure, both give a good distribution through the thickness when compared to the SSA, with BC2 being closest. 
Adopting the optimum mesh size, element type and the suitable boundary condition, three different options for interfacial connection to simulate the CLT panel are presented in the following subsections.

\subsubsection{Model 1: 3-ply CLT panel using fully bonded model}

The fully bonded model is shown in Fig. 7(a). The orientation of the layup and the fibers in each ply have important roles in determining the accuracy of the model. The fully bonded model the orientation of the fibers is defined from three parameters which are relative to each other; the layup orientation, the ply orientation and an additional rotation.

This method allows the definition of a reference orientation for the layup and a reference orientation for each ply in the layup. Furthermore, the direction of the fibers in a ply relative to the reference orientation of the ply can be specified [21].

\subsubsection{Model 2: 3-ply CLT panel using Cohesive elements}

Here, the CLT plies will be modelled as separate plies and bonded using cohesive elements to represent the glue or tie; this is defined as a mesh layer as shown in Fig. 7(b). The cohesive element is used to model adhesives between two components and to bind between different interfaces although they do not have any degree of freedom other than that for displacement [21]. In this model, the cohesive element used is an 8-node three-dimensional element (COH3D8). The material property for the cohesive element is set as linear elastic traction according to [23].

\subsubsection{Model 3: 3-ply CLT panel using Contact interaction}

In this model (Fig. 7(c)), contact interaction between the plies is directly applied and the material properties of the interaction can be defined, hence there is no need to create a section for the cohesive layer as in the previous case. 


\subsubsection{Case Study 1: Model 1, 2 and 3 Results}

Table 2 presents the comparison between the three models and the SSA. From this table, it is clear that Models 2 and 3 are very similar except for the transverse normal shear stresses although even these are close to each other. Model 2 is more accurate than Model 1 in comparison with the SSA.

In terms of the displacements predicted by each model, the results show that for Model 1 (as the CLT plies are assumed as one block, i.e. layers perfectly bonded), the structure is stiffer and the displacement is less than the theoretical value. On the other hand, in Model 2 when the cohesive element is used, the predicted behavior of the CLT tends towards the theoretical solution derived from the SSA, especially for the transverse shear stresses $\tau_{x z}$ and $\tau_{y z}$. For the reasons mentioned above, Model 2 with cohesive elements between the CLT plies will be adopted for the following case study.

After the sensitivity studies for the mesh size, element type and boundary condition are explored, the 3D solid element (C3D20) with the cohesive element (COH3D8) with 6mm mesh size is chosen. Fig. 8 shows the comparison between the distribution of the in- and outof plane displacements along the $x$ and $y$-axes for the SSA and FEM results at the top of the CLT panel. As can be observed from Table 3, very good agreements are obtained between the FEM and SSA, with relative errors $2.09 \%, 0.80 \%$ and $0.07 \%$ for the displacements $u, v$ and $w$, respectively.

\subsection{Case study 2: FEM model of 3-ply CLT panels with Simply-Supported sides under Uniformly Distributed Load}

In this section, the same number of plies and material properties of Case study 1 , with the Model 2 cohesive ply connection is used but with a $1 \mathrm{MPa}$ uniformly distributed load applied on the top of the panel. 
Table 4 shows the comparison between the SSA and the FEM results for all the displacements and the stress states for different locations. The FEM gives a generally good agreement with an average relative error equal to $1 \%$ with the SSA for the three-ply CLT. However, the results from the FEM models are inconsistent, with some parameters overestimated (such as; $v$ and $\tau_{y z}$ ) and others underestimated. Fig. 9 shows the in-plane stress $\sigma_{x}$ and the transverse shear stresses $\tau_{x z}$ and $\tau_{y z}$ obtained from the SSA and the FEM through the thickness of the panel. The FEM results show discontinuity of the transverse stresses $\tau_{x z}$ and $\tau_{y z}$ at the interfaces between the different plies (e.g. the bottom of the $1^{\text {st }}$ ply for the SSA is equal to the

top of the $2^{\text {nd }}$ ply, but for the FEM, it is not the case). This is due to the fact that using solid elements in ABAQUS will lead to discontinuity of the transverse shear stresses at ply interfaces [21]. Accurate evaluation of the shear stresses at each layer is important given the propensity of the CLT section to fail in rolling shear. Furthermore, the values of $\tau_{x z}$ should be equal to zero at the top and the bottom of the panel, however, this is not the case with the FEM results.

The FEM model is able to capture the theoretical structural response of the CLT panel with a good level of accuracy in comparison to the theoretically exact solution from the SSA. In the following case studies, the boundary condition is changed to three simply-supported sides and a free edge, the plate geometry and material properties are unchanged.

\subsection{Case study 3: FEM model of 3-ply CLT panels with three sides simply-supported and a free edge under Sinusoidal Load}

The panel has three sides simply-supported at $x=0, y=0$ and $b$ and a free edge at $x=a$, a sinusoidal load is applied to the top surface with a maximum magnitude of $1 \mathrm{MPa}(q(x, y)=$ $q_{0} \sin (\pi x / a) \sin (\pi y / b)$ where $\left.q_{0}=1 \mathrm{MPa}\right)$. 
Table 5 shows the comparison between the SSA and the FEM results for all the in- and outof-plane displacements and stresses. In general, the SSA predicts higher values than the FEM for all the displacements and the stresses but the results remain. The FEM shows discontinuity in the transverse shear stresses $\tau_{x z}$ and $\tau_{y z}$ between the plies while the SSA shows continuity.

\subsection{Case study 4: FEM model of 3-ply CLT panels with three sides simply- supported and a free edge under Uniformly Distributed Load (UDL)}

This case study comprises the same panel and boundary conditions as the previous, however, the load is now a uniformly distributed pressure load with a magnitude of $1 \mathrm{MPa}$. The resulting in-plane and out-of-plane stresses and displacements through the thickness of the three plies of CLT are shown in Table 6.

As per the previous case, the SSA results are higher than the FEM results, while still in relative agreement with an average relative error equal to $3 \%$. Additionally, the values of the displacements and the stresses for the uniformly distributed load are approximately twice the values of the sinusoidal load from Table 5. As mentioned in section 2.3, the same trends as the previous case study are observed with FEM displaying discontinuity in the transverse shear stresses in between the plies. Fig. 9(a) shows the in-plane stress $\sigma_{x}$ distribution through the thickness of the CLT by using the SSA and the FEM, both show good agreement with an average relative error equal to $2.5 \%$.

\subsection{Case study 5: 5-ply CLT beam examined by O'Dowd et al. [18]}

O'Dowd et al. examined the bending stiffness of a number of CLT panels experimentally. The focused panel examined here consisted of five laminae, with samples from each lamina being removed and subject to testing to obtain their modulus of elasticity parallel to the grain. Table 7 presents the modulus of elasticity parallel to the grain $\left(E_{1}\right)$ reported by [18], all other 
moduli given are based on the characteristic values for the respective timber grades given in EN 338 [20].

The focused panel was $1700 \mathrm{~mm}$ long $(1600 \mathrm{~mm}$ clear span $) \times 150 \mathrm{~mm}$ wide $\times 99 \mathrm{~mm}$ thick (each ply was $19 \mathrm{~mm}$ thick, each glue layer was $1 \mathrm{~mm}$ thick). Polyurethane glue was used to bond the laminae together, this had a longitudinal shear strength of $10 \mathrm{MPa}$ and a tensile strength perpendicular to the bond line of $5 \mathrm{MPa}[23]$.

The test set-up was based on that described in BS EN 408 [24] as shown in Fig. 10. In the experiment, the sample exhibited approximately linear behavior with the total out -of- plane maximum loading and the corresponding deflection recorded being $35.30 \mathrm{kN}$ and $25.83 \mathrm{~mm}$ respectively [18].

For the FEM model in this study, 3D 20 node element types with a cohesive element layer between the CLT plies and an element mesh size of $10.75 \mathrm{~mm}$ is used. Since the specimen thickness and span is larger than the panels previously investigated, a slightly larger element size was adopted in order to maintain computational efficiency.

As can be seen from Fig. 11, the FEM model gives a fairly good agreement with the experimental work, however, the response is slightly stiffer with a maximum of $10 \%$ error with the experimental result. The FEM curve shows more pronounced non-linearity due to the involvement of the shear effect with bending as a result of the beam thickness, some slight non-linearity was observed in the experimental results. There are a number of possible sources of error in the model including inaccuracies in the bond assumptions. As mentioned in section 1.1, the FEM models in this paper assume full bond along the short edges of the CLT boards. This will result in a stiffer response compared to the physical specimen where edge adhesive may not have been applied (no confirmation of edge gluing of the boards was given in the original experimental paper). 
In the experiment, the specimen failed in rolling shear. Typically, the characteristic rolling shear strength for CLT constructed using C24 softwood timber of this type is $\sim 0.75 \mathrm{~N} / \mathrm{mm}^{2}$ to $1.5 \mathrm{~N} / \mathrm{mm}^{2}$ [25 \& 26]. Fig. 12 shows the FEM derived horizontal shear stresses through the thickness of the panel at the peak load, this clearly indicates a rolling shear failure is predicted.

Another possible source of error in the model is the uncertainty in the material properties of each board making up the CLT panel. Despite tests being undertaken on each timber layer of the CLT panel, these were at discrete points and given that timber is a natural material, there remains uncertainty of the material properties throughout the panel, hence upper and lower $95^{\text {th }}$ percentiles of the modulus of elasticity are simulated in ABAQUS, as shown in Fig. 13. It can be observed that at a decrease in elastic modulus of $5 \%$ results in a much closer prediction.

\section{Conclusions}

FEM models were developed for a 3-ply CLT panel and a 5-ply CLT beam under out-ofplane loads. The modelling is able to predict all the in- and out- of plane displacements and stresses to a reasonable degree of accuracy. For cases 1-4, the FEM models were compared with the SSA, and with existing experimental data for case 5. From the comparison the following conclusions can be drawn:

- Among different element types, the 3D 20-node linear brick element gives more accurate results.

- The cohesive element mesh layer and the interaction contact models give almost the same results. Both are more accurate than the fully bonded method when taking the SSA results as the benchmark.

- The FEM results show discontinuity of the transverse stresses $\tau_{x z}$ and $\tau_{y z}$ at the interaction between the different plies, this problem is avoided with the SSA method. 
- For the specific cases studied, the developed FEM model can give a reasonable prediction of the maximum deflection of a CLT panel and is also able to predict the rolling shear failure mode observed experimentally.

- The FEM model for the case study of 3-ply CLT panels with three sides simply-supported and one free edge gave good agreement with the SSA results, although the FEM underestimated the in- and out-of-plane stresses and displacement. Also, the FEM showed discontinuity of the transverse stresses across the interfaces between different plies.

The conclusions above need to be viewed within the context of limitations of the models employed. As previously mentioned, for the FEM models, edge gluing of the boards making up each ply was not modelled, a full bond was assumed, hence the model would be expected to be stiffer. In the case of the SSA models, a full bond is assumed between plies on both the face and the edges.

In both the FE and SSA models, only elastic material behavior was considered. The models could be further extended to include appropriate failure criteria. Addressing these limitations forms part of the authors' ongoing work.

\section{Acknowledgements}

The authors gratefully acknowledge the contribution of the University of Petra, Jordan, to funding this research. The authors declare that there is no conflict of interest.

\section{References}

[1] Harris, R. 2015. Cross laminated timber, Wood Composites, Elsevier Ltd.

[2] McKenzie W.M.C. 2000. Design of structural timber, London, MACMILLAN Press Ltd.

[3] Stauder C. 2013. Cross-Laminated Timber: an analysis of the Austrian industry and ideas for fostering its development in America, Austria. 
[4] FPInnovations. 2013. CLT Handbook Canadian Edition, v53, Canada.

[5] Pearson, H.R. 2014. Cross-laminated timber panels incorporating angular material properties, University of Bath.

[6] Theil A. and Schickhofer G., 2010, CLT designer - A software tool for designing cross laminated timber elements: 1d-plate design, Proceedings of the World Conference on Timber Engineering, WCTE 2010, Riva del Garda, Italy, Cecotti A \& Van de Kuilen J., eds.

[7] Shahnewaz, M., Tannert, T., Alam, M.S. and Popovski, M. 2015. Experimental and finite element analysis of cross laminated timber (CLT) panels. First International Conference on Advances in Civil Infrastructure and Construction Materials.

[8] Serrano, E. and Enquist, B. 2010. Compression strength perpendicular to grain in Cross-laminated timber (CLT). WCTE, 1-8.

[9] BS EN 1991. 2008. Eurocode 5: Design of timber structures - Part 1-1: General Common rules and rules for buildings. British Standards Institution, Milton Keynes, UK.

[10] Vilguts, O.A., Serdjuks, D. and Pakrastins, L. 2015. Design methods of elements from cross-laminated timber subjected to flexure. Procedia Engineering, 117(1):10-19.

[11] Bogensperger, T. and Jöbstl, R.A. 2015. Concentrated load introduction in CLT elements perpendicular to plane. International Council for Research and Innovation in Building and Construction Working Commission W18 - Timber Structures Cib-W18, 1-16.

[12] Saavedra Flores, E.I., Dayyani, I., Ajaj, R.M., Castro-Triguero, R., DiazDelao, F.A., Das, R. and González Soto, P. 2015. Analysis of cross-laminated timber by computational homogenisation and experimental validation. Composite Structures, Elsevier Ltd., 121: 386-394.

[13] Wu, Z.J., Han, C. and Niu, Z. 2015. A 3D exact analysis of the boundary layer effect of asymmetric piezoelectric laminates with electromechanical coupling. International Journal of Solids and Structures, Elsevier Ltd., 72: 118-129.

[14] Albostami A., Wu ZJ., Cunningham L.S. 2019. Assessment of cross-laminated timber panels by the state-space approach. Advances in Structural Engineering, 22(11). doi: 10.1177/1369433219841504.

[15] Ye J. 2003. Laminated Composite Plates and Shells, London, Springer London.

[16] Sheng, H.Y. and Ye, J.Q. 2003. A three-dimensional state space finite element solution for laminated composite cylindrical shells. Computer Methods in Applied Mechanics and Engineering, 192(22-24): 2441-2459.

[17] Stroud K. A. 2013. Engineering Mathematics, $7^{\text {th }}$ edition. New York: Industrial Press Inc.

[18] O’Dowd B., Cunningham L.S. \& Nedwell P. 2016. Briefing: experimental and 
theoretical bending stiffness of cross-laminated timber panels. Proceedings of the Institution of Civil Engineers - Construction Materials, 169 (6), 77-281, doi: http://dx.doi.org/10.1680/jcoma.15.00063.

[19] Sturzenbecher R., Hofstetter K. 2011. Bending of cross-ply laminated composites: an accurate and efficient plate theory based upon models of Lekhnitskii and Ren. Composite Structures, 93: 1078-88.

[20] BS EN 338:2009. 2009. Structural timber - strength classes. British Standards Institution, Milton Keynes, UK.

[21] ABAQUS. 2013. User's Manual. v6.13, Dassault Systémes Simulia Corp., Providence, Rhode.

[22] Albostami A., Wu ZJ., Cunningham L.S. 2017. Structural behavior of CrossLaminated Timber panels by the State Space Approach. International Journal of Computational Methods and Experimental Measurements, 1-13.

[23] BS EN 15425:2008. 2008. Adhesives-One component polyurethane for load bearing timber structures- Classification and performance requirements. British Standards Institution, Milton Keynes, UK.

[24] BS EN 408:2010+A:2012. 2012. Timber structures-structural timber and glued laminated timber-determination of some physical and mechanical properties. British Standards Institution, Milton Keynes, UK.

[25] Zublin Timber, 2018, Leno Cross Laminated Timber Technical Brochure, Zublin Timber GmbH, Stuttgart, Germany.

[26] Ehrhart T. \& Brandner R., 2018 Rolling shear: test configurations and properties of some European soft and hardwood species, Engineering Structures, 172. 


\section{list of symbols}

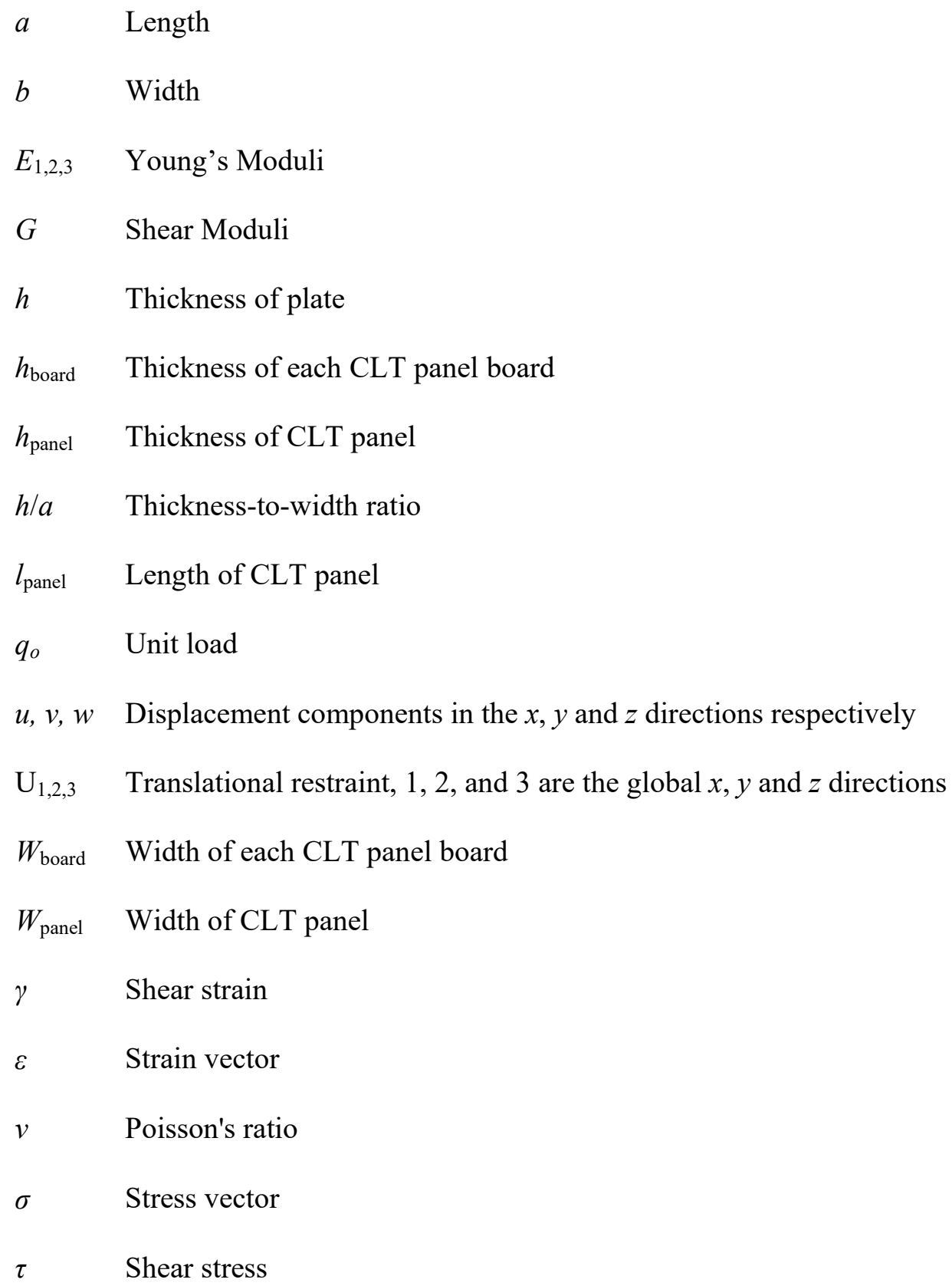




\section{List of Tables}

Table 1 Effect of element type and BC sensitivity on the displacements ( $\mathrm{mm})$ and stresses (MPa) of 3-ply CLT panel $(h / a=0.25)$.

\begin{tabular}{|c|c|c|c|c|c|c|}
\hline & \multirow[b]{2}{*}{$(x, y)$} & \multirow[b]{2}{*}{$z$} & \multirow[b]{2}{*}{ SSA } & \multicolumn{3}{|c|}{ FEM } \\
\hline & & & & $\begin{array}{c}\text { BC 1 } \\
\text { (C3D20) } \\
\end{array}$ & $\begin{array}{c}\text { BC 2 } \\
\text { (C3D20) } \\
\end{array}$ & $\begin{array}{c}\text { BC 2 } \\
\text { (C3D8) } \\
\end{array}$ \\
\hline \multirow{2}{*}{$u$} & \multirow{2}{*}{$\left(\frac{a}{2}, 0\right)$} & ${ }^{*} \mathrm{~T}$ & 0.1246 & 0.1251 & 0.1272 & 0.1283 \\
\hline & & ${ }^{*} \mathrm{~B}$ & -0.1240 & -0.1607 & -0.1272 & -0.1283 \\
\hline \multirow{2}{*}{$v$} & \multirow{2}{*}{$\left(0, \frac{b}{2}\right)$} & ${ }^{*} \mathrm{~T}$ & 0.1870 & 0.2801 & 0.2121 & 0.2148 \\
\hline & & "B & -0.2138 & -0.2520 & -0.2121 & -0.2148 \\
\hline \multirow{2}{*}{$w$} & \multirow{2}{*}{$\left(\frac{a}{2}, \frac{b}{2}\right)$} & ${ }^{*} \mathrm{~T}$ & 0.9943 & 1.0753 & 0.9936 & 0.9988 \\
\hline & & ${ }^{*} \mathrm{~B}$ & 0.9168 & 0.9935 & 0.9143 & 0.9200 \\
\hline \multirow{2}{*}{$\sigma_{x}$} & \multirow{2}{*}{$\left(\frac{a}{2}, \frac{b}{2}\right)$} & ${ }^{*} \mathrm{~T}$ & -13.0319 & -14.3495 & -13.0035 & -11.2076 \\
\hline & & ${ }^{*} \mathrm{~B}$ & 12.2872 & 13.7223 & 12.2756 & 10.6314 \\
\hline \multirow{2}{*}{${ }^{* *} \sigma_{y}$} & \multirow{2}{*}{$\left(\frac{a}{2}, \frac{b}{2}\right)$} & ${ }^{*} \mathrm{~T}$ & -10.1361 & -10.9284 & -10.0436 & -9.8312 \\
\hline & & ${ }^{*} \mathrm{~B}$ & 10.6190 & 11.7134 & 10.6640 & 10.5847 \\
\hline \multirow[b]{2}{*}{$\tau_{x y}$} & \multirow{2}{*}{$(0,0)$} & ${ }^{*} \mathrm{~T}$ & 1.8764 & 1.1808 & 2.0314 & 2.0499 \\
\hline & & ${ }^{*} \mathrm{~B}$ & -2.0339 & -1.1809 & -2.0314 & -2.0499 \\
\hline$\tau_{x z}$ & $\left(\frac{a}{2}, 0\right)$ & $h / 2$ & 0.7242 & 0.8756 & 0.7127 & 0.7553 \\
\hline$\tau_{y z}$ & $\left(0, \frac{b}{2}\right)$ & $h / 2$ & 1.0865 & 1.2238 & 0.9827 & 1.0294 \\
\hline
\end{tabular}

${ }^{*}$ Where $\mathrm{T}$ and $\mathrm{B}$ are the top and bottom of the panel through the thickness respectively.

${ }^{* *}$ The values of $\sigma_{y}$ are the top and bottom of the $2^{\text {nd }}$ layer $\left(\theta=90^{\circ}\right)$. 
Table 2 Case Study 1: FEM and SSA results for displacements (mm) and stresses (MPa)

\begin{tabular}{|c|c|c|c|c|c|c|}
\hline & \multirow{2}{*}{$(x, y)$} & \multirow{2}{*}{$z$} & \multirow{2}{*}{ SSA } & \multicolumn{3}{|c|}{${ }^{* * *}$ FEM } \\
\hline & & & & Model 1 & Model 2 & Model 3 \\
\hline \multirow{2}{*}{$\boldsymbol{u}$} & \multirow{2}{*}{$\left(\frac{a}{2}, 0\right)$} & ${ }^{*} \mathrm{~T}$ & 0.1246 & 0.0871 & 0.1272 & 0.1272 \\
\hline & & ${ }^{*} \mathrm{~B}$ & -0.1240 & -0.0871 & -0.1272 & -0.1272 \\
\hline \multirow{2}{*}{$v$} & \multirow{2}{*}{$\left(0, \frac{b}{2}\right)$} & ${ }^{*} \mathrm{~T}$ & 0.1870 & 0.0848 & 0.2121 & 0.2120 \\
\hline & & ${ }^{*} \mathrm{~B}$ & -0.2138 & -0.0848 & -0.2121 & -0.2121 \\
\hline \multirow[b]{2}{*}{$w$} & \multirow{2}{*}{$\left(\frac{a}{2}, \frac{b}{2}\right)$} & ${ }^{*} \mathrm{~T}$ & 0.9943 & 0.4523 & 0.9936 & 0.9936 \\
\hline & & *B & 0.9168 & 0.3772 & 0.9143 & 0.9143 \\
\hline \multirow[b]{2}{*}{$\sigma_{x}$} & \multirow{2}{*}{$\left(\frac{a}{2}, \frac{b}{2}\right)$} & ${ }^{*} \mathrm{~T}$ & -13.0319 & -9.2528 & -13.0035 & -13.0035 \\
\hline & & ${ }^{*} \mathrm{~B}$ & 12.2872 & 8.5113 & 12.2756 & 12.2756 \\
\hline \multirow{2}{*}{${ }^{* *} \sigma_{y}$} & \multirow{2}{*}{$\left(\frac{a}{2}, \frac{b}{2}\right)$} & ${ }^{*} \mathrm{~T}$ & -10.1361 & -8.3951 & -10.0436 & -10.0436 \\
\hline & & *B & 10.6190 & 8.3277 & 10.6640 & 10.6640 \\
\hline \multirow[b]{2}{*}{$\tau_{x y}$} & \multirow{2}{*}{$(0,0)$} & ${ }^{*} \mathrm{~T}$ & 1.8764 & 1.0335 & 2.0314 & 2.0312 \\
\hline & & *B & -2.0339 & -1.0335 & -2.0314 & -2.0311 \\
\hline$\tau_{x z}$ & $\left(\frac{a}{2}, 0\right)$ & $h / 2$ & 0.7242 & 0.1208 & 0.7127 & 0.7223 \\
\hline$\tau_{y z}$ & $\left(0, \frac{b}{2}\right)$ & $h / 2$ & 1.0865 & 1.7858 & 0.9827 & 1.1138 \\
\hline
\end{tabular}

${ }^{*}$ Where $\mathrm{T}$ and $\mathrm{B}$ are the top and bottom of the panel through the thickness respectively.

${ }^{* *}$ The values of $\sigma_{y}$ are the top and bottom of the $2^{\text {nd }}$ layer $\left(\theta=90^{\circ}\right)$.

${ }^{* * *}$ The FEM model is 3D 20-node linear brick element (C3D20) with mesh element size $6 \mathrm{~mm}$.

Table 3 Case Study 1: FEM and SSA results for displacements $(\mathrm{mm})$ at $z=0.0$.

\begin{tabular}{ccccc}
\hline & $(\boldsymbol{x}, \boldsymbol{y})$ & SSA & ${ }^{* *}$ FEM & Relative errors \\
\hline $\boldsymbol{u}$ & $\mathbf{( \frac { \mathbf { a } } { \mathbf { 2 } } \mathbf { 0 } )}$ & 0.1246 & 0.1272 & 2.09 \\
\hline $\boldsymbol{v}$ & $\left(\mathbf{0}, \frac{\boldsymbol{b}}{\mathbf{2}}\right)$ & 0.2138 & 0.2121 & -0.80 \\
\hline $\boldsymbol{w}$ & $\left(\mathbf{a} \frac{\mathbf{a}}{\mathbf{2}}, \mathbf{2}\right.$ & 0.9943 & 0.9936 & -0.07 \\
\hline
\end{tabular}

${ }^{*}$ Where $\mathrm{T}$ and $\mathrm{B}$ are the top and bottom of the panel through the thickness respectively.

${ }^{* *}$ The FEM model is 3D 20-node linear brick element (C3D20) with mesh element size $6 \mathrm{~mm}$. 
Table 4 Case Study 2: In- and out-of-plane displacements (mm) and stress states (MPa) predicted by SSA and FEM.

\begin{tabular}{|c|c|c|c|c|c|c|c|c|c|}
\hline & $(x, y)$ & $\begin{array}{l}\text { Number of } \\
\text { the ply }\end{array}$ & $z$ & SSA & ${ }^{* *}$ FEM & & & SSA & ${ }^{* *}$ FEM \\
\hline \multirow{6}{*}{$\boldsymbol{u}$} & \multirow{6}{*}{$\left(\frac{a}{2}, 0\right)$} & \multirow{2}{*}{$1^{\text {st }}$ Ply } & ${ }^{*} \mathrm{~T}$ & 0.2512 & 0.2167 & \multirow{6}{*}{$v$} & \multirow{6}{*}{$\left(0, \frac{b}{2}\right)$} & 0.2954 & 0.3089 \\
\hline & & & ${ }^{*} \mathrm{~B}$ & -0.1862 & -0.2167 & & & 0.1811 & 0.1851 \\
\hline & & $2^{\text {nd }} \mathrm{Pl}_{\mathrm{y}}$ & ${ }^{*} \mathrm{~T}$ & -0.1862 & -0.1543 & & & 0.1811 & 0.1851 \\
\hline & & 2. Ply & ${ }^{*} \mathrm{~B}$ & 0.1479 & 0.1543 & & & -0.2025 & -0.1851 \\
\hline & & $3^{\mathrm{rd}} \mathrm{Pl}$ & ${ }^{*} \mathrm{~T}$ & 0.1479 & 0.1952 & & & -0.2025 & -0.1849 \\
\hline & & 3. Ply & ${ }^{*} \mathrm{~B}$ & -0.2131 & -0.1952 & & & -0.3674 & -0.3572 \\
\hline \multirow{6}{*}{$w$} & \multirow{6}{*}{$\left(\frac{a}{2}, \frac{b}{2}\right)$} & $1^{\mathrm{st}} \mathrm{Ply}$ & ${ }^{*} \mathrm{~T}$ & 1.9931 & 1.5113 & \multirow{6}{*}{$\sigma_{x}$} & \multirow{6}{*}{$\left(\frac{a}{2}, \frac{b}{2}\right)$} & -18.2685 & -18.0570 \\
\hline & & 1. Ply & ${ }^{*} \mathrm{~B}$ & 1.7317 & 1.5057 & & & 12.0051 & 12.0933 \\
\hline & & nd $\mathrm{Pl}_{\mathrm{H}}$ & ${ }^{*} \mathrm{~T}$ & 1.7317 & 1.5065 & & & -0.2387 & -0.2352 \\
\hline & & 2 Ply & ${ }^{*} \mathrm{~B}$ & 1.6328 & 1.4721 & & & -0.3774 & -0.3708 \\
\hline & & ${ }^{\mathrm{rd}} \mathrm{Dl}$ & ${ }^{*} \mathrm{~T}$ & 1.6328 & 1.4720 & & & -11.8776 & -11.6885 \\
\hline & & 3 Рту & ${ }^{*} \mathrm{~B}$ & 1.5621 & 1.4248 & & & 18.2443 & 18.1924 \\
\hline \multirow{6}{*}{$\sigma_{y}$} & \multirow{6}{*}{$\left(\frac{a}{2}, \frac{b}{2}\right)$} & ${ }^{\text {st }} \mathrm{Pl}$ & ${ }^{*} \mathrm{~T}$ & -1.8828 & -1.8396 & \multirow{6}{*}{$\tau_{x y}$} & \multirow{6}{*}{$(0,0)$} & 4.1017 & 4.3203 \\
\hline & & & ${ }^{*} \mathrm{~B}$ & -0.7354 & -0.7281 & & & -0.2632 & -0.2424 \\
\hline & & $2^{\text {nd }} \mathrm{Pl}_{\mathrm{y}}$ & ${ }^{*} \mathrm{~T}$ & -13.9692 & -13.7273 & & & -0.2632 & -0.2424 \\
\hline & & 2u Ply & ${ }^{*} \mathrm{~B}$ & 14.7099 & 14.8148 & & & -0.3209 & -0.2919 \\
\hline & & ${ }^{\mathrm{rd}} \mathrm{Pl} \mathrm{y}_{\mathrm{Y}}$ & ${ }^{*} \mathrm{~T}$ & 0.1310 & 0.1403 & & & -0.3209 & -0.2919 \\
\hline & & 3 Ply & ${ }^{*} \mathrm{~B}$ & 1.2603 & 1.2746 & & & -3.6199 & -3.6184 \\
\hline \multirow{6}{*}{$\tau_{x z}$} & \multirow{6}{*}{$\left(0, \frac{b}{2}\right)$} & 1st $\mathrm{D} 1$. & ${ }^{*} \mathrm{~T}$ & 0.0000 & -0.0604 & \multirow{6}{*}{$\tau_{y z}$} & \multirow{6}{*}{$\left(\frac{a}{2}, 0\right)$} & 0.0000 & 0.0000 \\
\hline & & ${ }^{n}$ Ply & ${ }^{*} \mathrm{~B}$ & 1.1439 & 1.2216 & & & 1.1590 & 1.1890 \\
\hline & & & ${ }^{*} \mathrm{~T}$ & 1.1439 & 1.1490 & & & 1.1590 & 1.5002 \\
\hline & & $2^{\text {110 }}$ Ply & ${ }^{*} \mathrm{~B}$ & 1.2696 & 1.3339 & & & 0.6757 & 0.7091 \\
\hline & & \multirow{2}{*}{$3^{\text {rd }} \mathrm{Ply}$} & ${ }^{*} \mathrm{~T}$ & 1.2696 & 1.3494 & & & 0.6757 & 0.6565 \\
\hline & & & ${ }^{*} \mathrm{~B}$ & 0.0000 & 0.0812 & & & 0.0000 & 0.0151 \\
\hline
\end{tabular}

${ }^{*}$ Where $\mathrm{T}$ and $\mathrm{B}$ are the top and bottom of the plies through the thickness respectively.

${ }^{* *}$ All the FEM models use 3D 20-node linear brick elements (C3D20) with mesh size $6 \mathrm{~mm}$. 
Table 5 Case Study 3: In- and out-of-plane displacements $(\mathrm{mm})$ and stress states (MPa) predicted by SSA and FEM.

\begin{tabular}{|c|c|c|c|c|c|c|c|c|c|}
\hline & $(x, y)$ & $\begin{array}{c}\text { Number of } \\
\text { the ply }\end{array}$ & $z$ & SSA & ${ }^{* *}$ FEM & & & SSA & ${ }^{* *}$ FEM \\
\hline \multirow{5}{*}{$u$} & \multirow{5}{*}{$\left(\frac{a}{2}, 0\right)$} & $1^{\text {st }}$ Ply & $\begin{array}{l}{ }^{*} \mathrm{~T} \\
{ }^{*} \mathrm{~B}\end{array}$ & $\begin{array}{c}0.2458 \\
-0.0970\end{array}$ & $\begin{array}{c}0.2432 \\
-0.0791\end{array}$ & \multirow{5}{*}{$v$} & \multirow{5}{*}{$\left(0, \frac{b}{2}\right)$} & $\begin{array}{c}0.5786 \\
-0.2452\end{array}$ & $\begin{array}{c}0.5732 \\
-0.2450\end{array}$ \\
\hline & & $2^{\text {nd }} \mathrm{P} l_{\mathrm{y}}$ & ${ }^{*} \mathrm{~T}$ & -0.0970 & -0.0791 & & & 0.2452 & 0.2450 \\
\hline & & 2 Ply & *B & 0.0830 & 0.0719 & & & -0.2294 & -0.2262 \\
\hline & & $3^{\text {rd }} \mathrm{Pl} \mathrm{y}_{4}$ & ${ }^{*} \mathrm{~T}$ & 0.0830 & 0.0719 & & & -0.2294 & -0.2262 \\
\hline & & 3 Рाy & ${ }^{*} \mathrm{~B}$ & -0.2398 & -0.2373 & & & -0.5525 & -0.5489 \\
\hline \multirow{6}{*}{$w$} & \multirow{6}{*}{$\left(\frac{a}{2}, \frac{b}{2}\right)$} & $1^{\mathrm{st}} \mathrm{P} \mathrm{l}_{\mathrm{s}}$ & ${ }^{*} \mathrm{~T}$ & 2.1364 & 2.1174 & \multirow{6}{*}{$\sigma_{x}$} & \multirow{6}{*}{$\left(\frac{a}{2}, \frac{b}{2}\right)$} & -9.4205 & -9.2012 \\
\hline & & 1.Ply & ${ }^{*} \mathrm{~B}$ & 2.0978 & 2.0614 & & & 6.8563 & 6.6015 \\
\hline & & $2^{\text {nd }} \mathrm{P} l_{Y}$ & ${ }^{*} \mathrm{~T}$ & 2.0978 & 2.0614 & & & -0.5742 & -0.5730 \\
\hline & & 2 Ply & ${ }^{*} \mathrm{~B}$ & 2.0902 & 2.0562 & & & 0.4647 & 0.4734 \\
\hline & & ${ }^{2 \text { rd }} \mathrm{D} 1$ & ${ }^{*} \mathrm{~T}$ & 2.0902 & 2.0562 & & & -6.1605 & -5.9002 \\
\hline & & 3 Рाy & ${ }^{*} \mathrm{~B}$ & 2.0617 & 2.0517 & & & 8.6928 & 8.5826 \\
\hline \multirow{6}{*}{$\sigma_{y}$} & \multirow{6}{*}{$\left(\frac{a}{2}, \frac{b}{2}\right)$} & & ${ }^{*} \mathrm{~T}$ & -2.3705 & -2.3310 & \multirow{6}{*}{$\tau_{x y}$} & \multirow{6}{*}{$(0,0)$} & 3.4633 & 3.4270 \\
\hline & & $1^{\text {sin }}$ Ply & ${ }^{*} \mathrm{~B}$ & -1.0488 & -1.0314 & & & 0.42820 & 0.4000 \\
\hline & & $2^{\text {nd }}$ & ${ }^{*} \mathrm{~T}$ & -21.9300 & -22.7521 & & & -0.4820 & -0.4000 \\
\hline & & 2. Ply & ${ }^{*} \mathrm{~B}$ & 24.3113 & 23.6217 & & & 0.5483 & 0.5392 \\
\hline & & & ${ }^{*} \mathrm{~T}$ & 0.7333 & 0.7316 & & & -0.5483 & -0.5392 \\
\hline & & 3 Ply & ${ }^{*} \mathrm{~B}$ & 1.9334 & 1.8996 & & & -3.7150 & -3.5900 \\
\hline \multirow{6}{*}{$\tau_{x z}$} & \multirow{6}{*}{$\left(0, \frac{b}{2}\right)$} & $1^{\text {st }} \mathrm{P} l_{\mathrm{V}}$ & ${ }^{*} \mathrm{~T}$ & 0.0000 & 0.0237 & \multirow{6}{*}{$\tau_{y z}$} & \multirow{6}{*}{$\left(\frac{a}{2}, 0\right)$} & 0.0000 & 0.0177 \\
\hline & & I"Ply & ${ }^{*} \mathrm{~B}$ & 0.8334 & 0.8086 & & & 0.4640 & 0.4114 \\
\hline & & $2^{\text {nd }} \mathrm{Pl} y$ & ${ }^{*} \mathrm{~T}$ & 0.8334 & 0.7745 & & & 0.4640 & 0.5258 \\
\hline & & 2. Ply & ${ }^{*} \mathrm{~B}$ & 0.8921 & 0.8613 & & & 0.3695 & 0.3750 \\
\hline & & $3^{\text {rd }} \mathrm{Ply}$ & ${ }^{*} \mathrm{~T}$ & 0.8921 & 0.8774 & & & 0.3695 & 0.3642 \\
\hline & & 3 Рाy & ${ }^{*} \mathrm{~B}$ & 0.0000 & 0.0364 & & & 0.0000 & 0.0032 \\
\hline
\end{tabular}

${ }^{*}$ Where $\mathrm{T}$ and $\mathrm{B}$ are the top and bottom of the plies through the thickness respectively.

${ }^{* *}$ All the FEM models use 3D 20-node linear brick elements (C3D20) with mesh size $6 \mathrm{~mm}$. 
Table 6 Case Study 4: In- and out-of-plane displacements (mm) and stress states (MPa) predicted by SSA and FEM.

\begin{tabular}{|c|c|c|c|c|c|c|c|c|c|}
\hline & $(x, y)$ & $\begin{array}{c}\text { Number of } \\
\text { the ply }\end{array}$ & $z$ & SSA & ${ }^{* *}$ FEM & & & SSA & ${ }^{* *}$ FEM \\
\hline \multirow{6}{*}{$\boldsymbol{u}$} & \multirow{6}{*}{$\left(\frac{a}{2}, 0\right)$} & & ${ }^{*} \mathrm{~T}$ & 0.4651 & 0.4618 & \multirow{6}{*}{$v$} & \multirow{6}{*}{$\left(0, \frac{b}{2}\right)$} & 1.1404 & 1.1259 \\
\hline & & $1^{\text {din }}$ Ply & ${ }^{*} \mathrm{~B}$ & -0.1602 & -0.1203 & & & 0.5581 & 0.5567 \\
\hline & & & ${ }^{*} \mathrm{~T}$ & -0.1602 & -0.1203 & & & 0.5581 & 0.5567 \\
\hline & & $2^{104}$ Ply & ${ }^{*} \mathrm{~B}$ & 0.1125 & 0.1010 & & & -0.4589 & -0.4568 \\
\hline & & & ${ }^{*} \mathrm{~T}$ & 0.1125 & 0.1010 & & & -0.4589 & -0.4568 \\
\hline & & 5 Ply & ${ }^{*} \mathrm{~B}$ & -0.4492 & -0.4492 & & & -1.0868 & -1.0713 \\
\hline \multirow{6}{*}{$w$} & \multirow{6}{*}{$\left(\frac{a}{2}, \frac{b}{2}\right)$} & ${ }^{\text {st }} \mathrm{Pl}$ & ${ }^{*} \mathrm{~T}$ & 4.5258 & 4.4845 & \multirow{6}{*}{$\sigma_{x}$} & \multirow{6}{*}{$\left(\frac{a}{2}, \frac{b}{2}\right)$} & -10.8941 & -10.8707 \\
\hline & & I. Ply & ${ }^{*} \mathrm{~B}$ & 4.4804 & 4.4283 & & & 5.0770 & 4.4411 \\
\hline & & $2^{\text {nd }} \mathrm{Pl}_{\mathrm{y}}$ & ${ }^{*} \mathrm{~T}$ & 4.4804 & 4.4283 & & & -1.0180 & -0.9961 \\
\hline & & $2^{\text {Ply }}$ & ${ }^{*} \mathrm{~B}$ & 4.3894 & 4.4141 & & & 0.4485 & 0.4267 \\
\hline & & $3^{\text {rd }} \mathrm{Pl}$ & ${ }^{*} \mathrm{~T}$ & 4.3894 & 4.4141 & & & -5.3133 & -4.4411 \\
\hline & & & ${ }^{*} \mathrm{~B}$ & 4.3890 & 4.3400 & & & 10.5695 & 10.8675 \\
\hline \multirow{6}{*}{$\sigma_{y}$} & \multirow{6}{*}{$\left(\frac{a}{2}, \frac{b}{2}\right)$} & $1^{\text {st }} \mathrm{p} l_{\mathrm{V}}$ & ${ }^{*} \mathrm{~T}$ & -4.2652 & $\begin{array}{l}-4.2241 \\
\end{array}$ & \multirow{6}{*}{$\tau_{x y}$} & \multirow{6}{*}{$(0,0)$} & 7.6243 & 7.5607 \\
\hline & & I Ply $^{\mathrm{s}}$ & ${ }^{*} \mathrm{~B}$ & -1.9857 & -1.9811 & & & 0.5445 & 0.5410 \\
\hline & & & ${ }^{*} \mathrm{~T}$ & -46.2344 & -46.0482 & & & -0.5445 & -0.5410 \\
\hline & & $2^{1 \mathrm{Ic}}$ Ply & ${ }^{*} \mathrm{~B}$ & 47.5175 & 47.5051 & & & 1.1608 & 1.1466 \\
\hline & & $3^{\text {rd }} \mathrm{Ply}$ & ${ }^{*} \mathrm{~T}$ & 1.3747 & 1.3369 & & & -1.1608 & -1.1466 \\
\hline & & 3 Ply & ${ }^{*} \mathrm{~B}$ & 3.7774 & 3.6138 & & & -7.0645 & -6.9494 \\
\hline \multirow{6}{*}{$\tau_{x z}$} & \multirow{6}{*}{$\left(0, \frac{b}{2}\right)$} & & ${ }^{*} \mathrm{~T}$ & 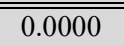 & -0.0825 & \multirow{6}{*}{\multicolumn{2}{|c|}{$\tau_{y z} \quad\left(\frac{a}{2}, 0\right)$}} & 0.0000 & 0.0000 \\
\hline & & $1^{\text {st }}$ Ply & ${ }^{*} \mathrm{~B}$ & 1.4299 & 1.3969 & & & 1.1590 & 1.1890 \\
\hline & & & ${ }^{*} \mathrm{~T}$ & 1.4299 & 1.2766 & & & 1.1590 & 1.5002 \\
\hline & & $2^{20}$ Ply & ${ }^{*} \mathrm{~B}$ & 1.5870 & 1.4984 & & & 0.6757 & 0.7091 \\
\hline & & \multirow{2}{*}{$3^{\text {rd }} \mathrm{Ply}$} & ${ }^{*} \mathrm{~T}$ & 1.5870 & 1.5286 & & & 0.6757 & 0.6565 \\
\hline & & & ${ }^{*} \mathrm{~B}$ & 0.0000 & 0.0836 & & & 0.0000 & 0.0151 \\
\hline
\end{tabular}

Table 7 Case Study 5: Material Properties [18].

\begin{tabular}{|c|c|c|}
\hline Lamina $(1)=$ Lamin & Lamina (3) & Lamina $(2)=$ Lamina $(4)$ \\
\hline C24 & C16 & $\mathrm{C} 24$ \\
\hline$E_{1}=11880 \mathrm{MPa}$ & $E_{1}=8980 \mathrm{MPa}$ & $E_{1}=14480 \mathrm{MPa}$ \\
\hline$E_{2}=370 \mathrm{MPa}$ & $E_{2}=270 \mathrm{MPa}$ & $E_{2}=370 \mathrm{MPa}$ \\
\hline$E_{3}=370 \mathrm{MPa}$ & $E_{3}=270 \mathrm{MPa}$ & $E_{3}=370 \mathrm{MPa}$ \\
\hline$G_{12}=690 \mathrm{MPa}$ & $G_{12}=500 \mathrm{MPa}$ & $G_{12}=690 \mathrm{MPa}$ \\
\hline$G_{13}=690 \mathrm{MPa}$ & $G_{13}=500 \mathrm{MPa}$ & $G_{13}=690 \mathrm{MPa}$ \\
\hline$G_{23}=50 \mathrm{MPa}$ & $G_{23}=36 \mathrm{MPa}$ & $G_{23}=50 \mathrm{MPa}$ \\
\hline \multicolumn{3}{|c|}{$v_{12}=0.44 ; v_{13}=0.44 ; v_{23}=0.64$ (For all the laminas) } \\
\hline \multicolumn{2}{|c|}{$\longrightarrow \mathrm{Y}$} & \\
\hline \multirow{5}{*}{$\mathrm{Z}$} & & $\operatorname{Lamina}(1) \mathrm{C} 24-0^{\circ}$ \\
\hline & & $\operatorname{Lamina}(2) \mathrm{C} 24-90^{\circ}$ \\
\hline & & $\operatorname{Lamina}(3) \mathrm{C} 16-0^{\circ}$ \\
\hline & & $\operatorname{Lamina}(4) \mathrm{C} 24-90^{\circ}$ \\
\hline & & $\operatorname{Lamina}(5) \mathrm{C} 24-0^{\circ}$ \\
\hline
\end{tabular}




\section{List of Figures}

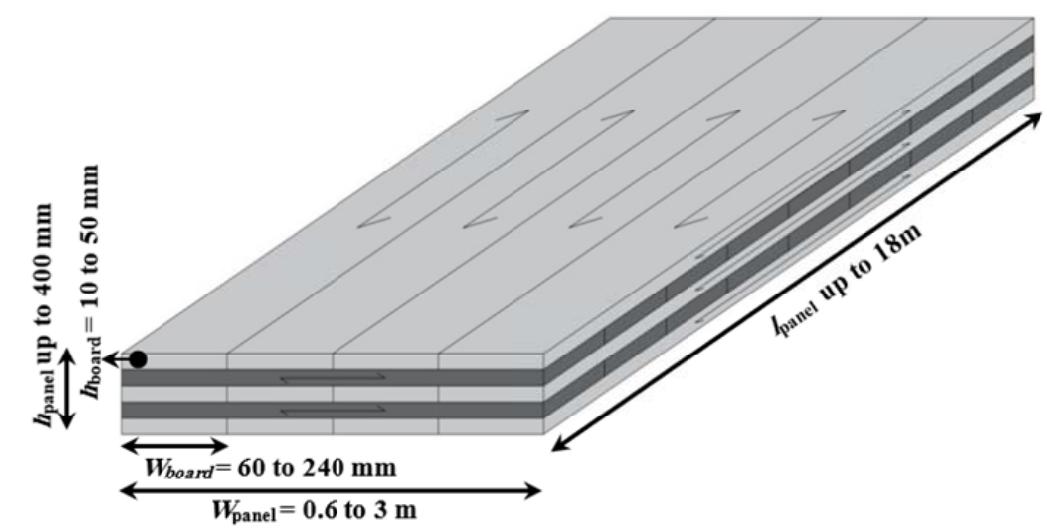

Fig. 1. Typical CLT panel arrangement and practical dimensions.

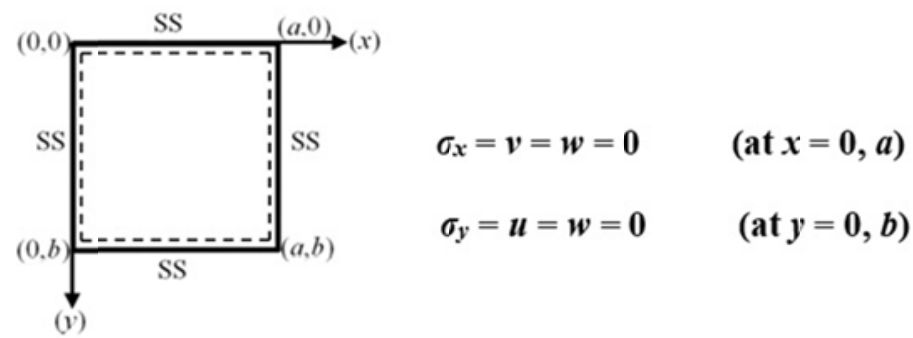

Fig. 2. Boundary conditions of plate.
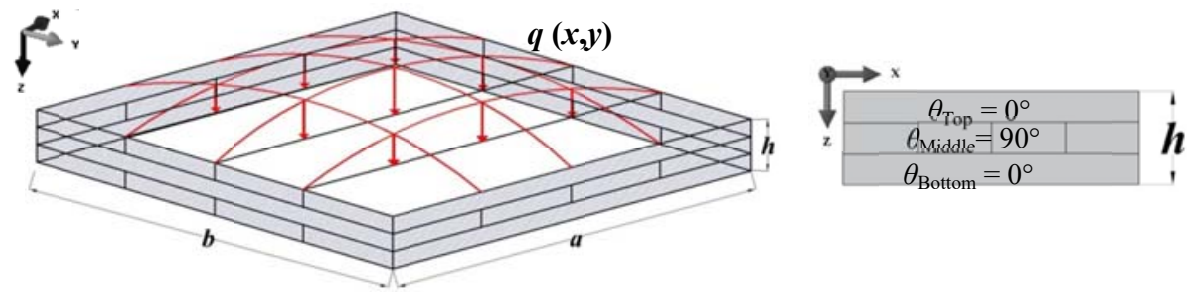

Fig. 3. Geometry of the 3-ply CLT panel under sinusoidal loading and the grain orientation through $h$. 


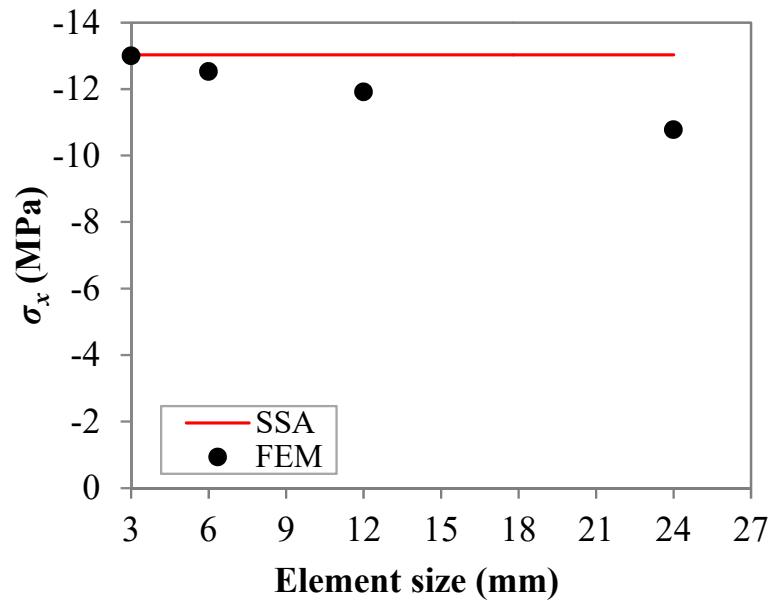

Fig. 4. Different mesh size results for the in-plane stresses $\sigma_{x}$ at $z=0.0$ for the 3-ply CLT panel.

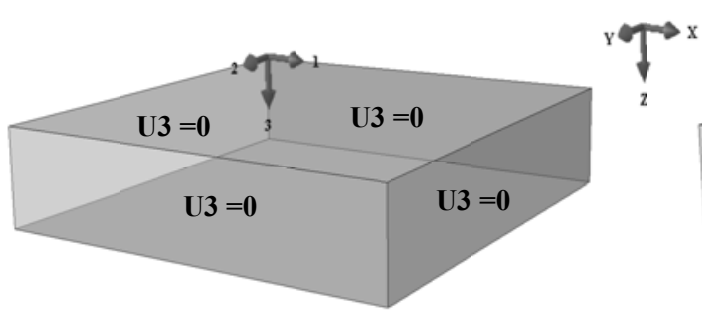

(a) $\mathrm{BC} 1$

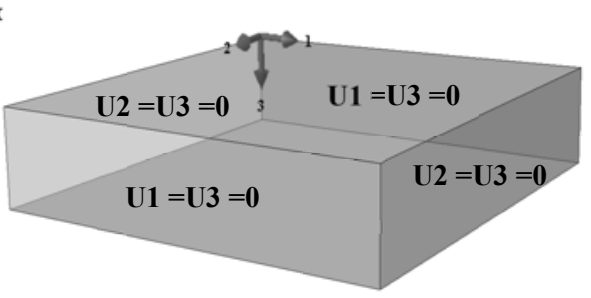

(b) $\mathrm{BC} 2$

Fig. 5. Different options for a simply-supported boundary condition.

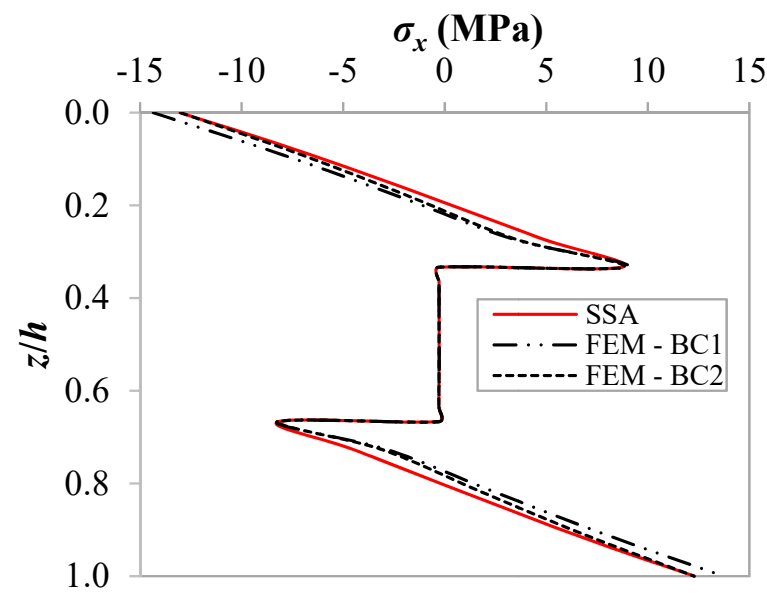

Fig. 6. Effect of BCs on the 3-ply CLT $\sigma_{x}$ through the thickness for $h / a=0.25$. 


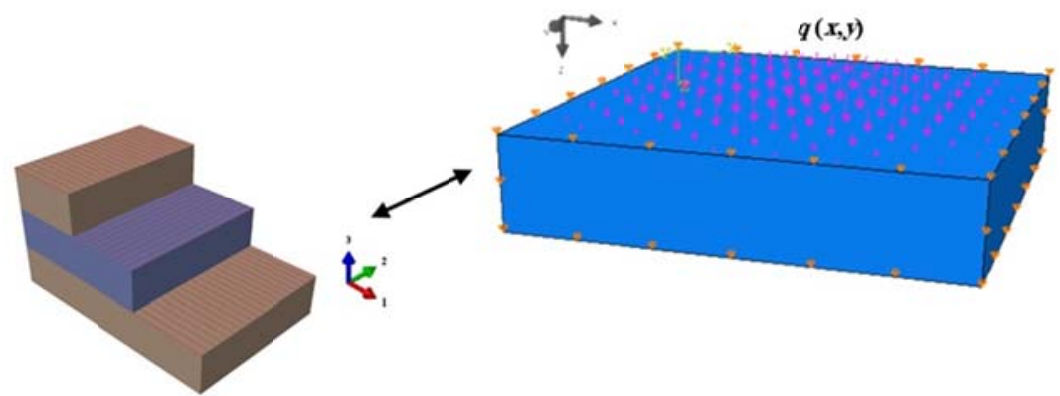

(a)

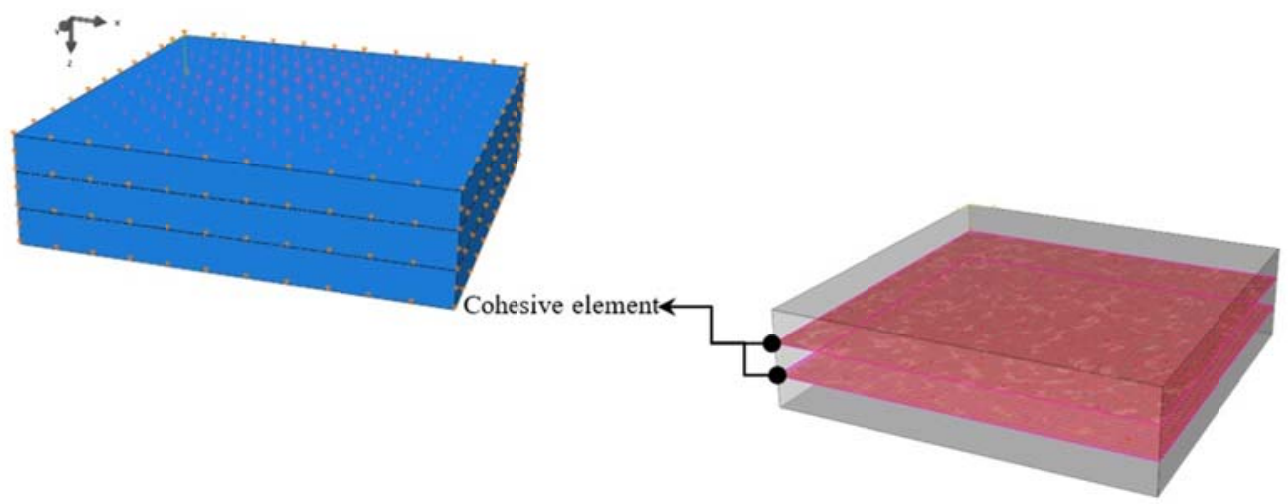

(b)

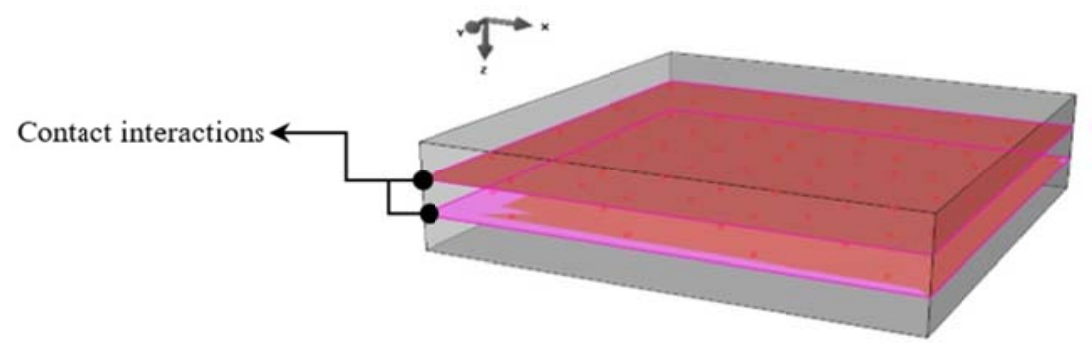

(c)

Fig. 7. FEM models for 3-ply CLT panel under sinusoidal load: (a) Model 1: fully bonded model, (b) Model 2: cohesive element layers between the CLT plies and (c) Model 3: contact interaction layers between the CLT plies. 


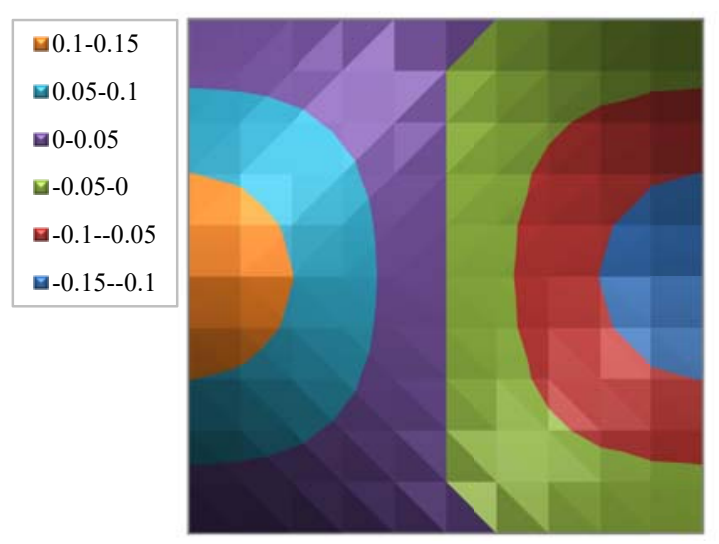

(a)

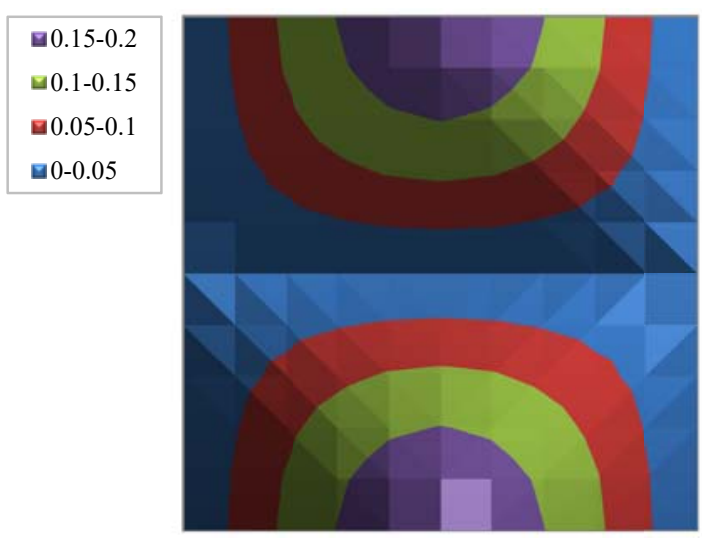

(c)

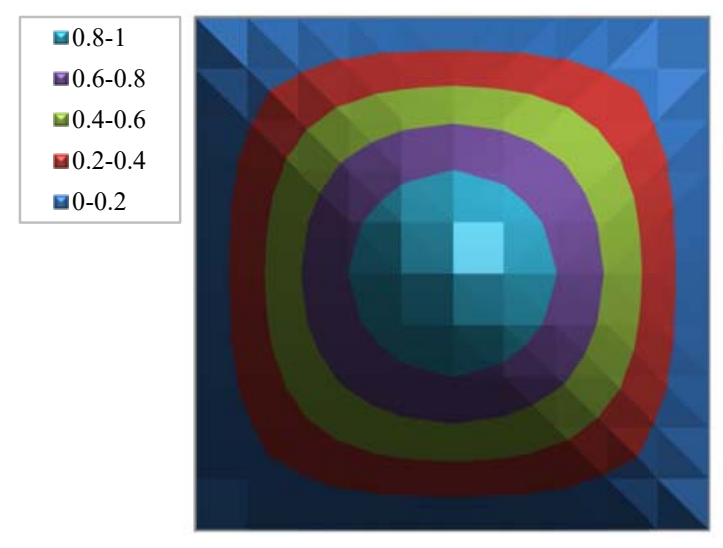

(e)

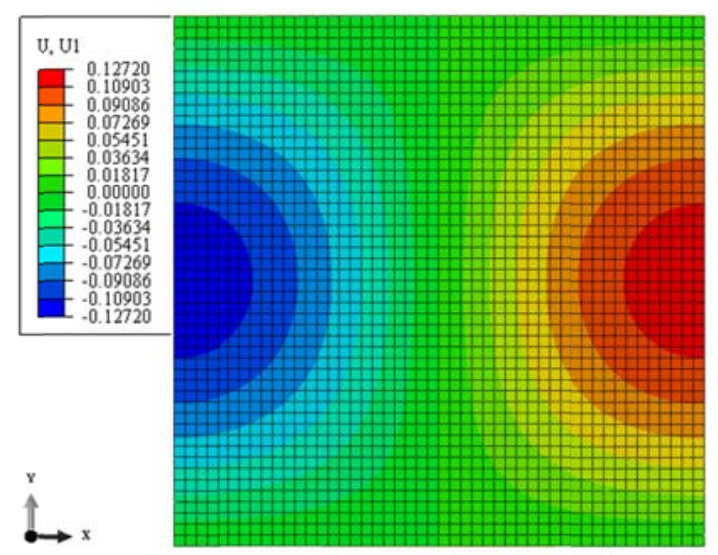

(b)

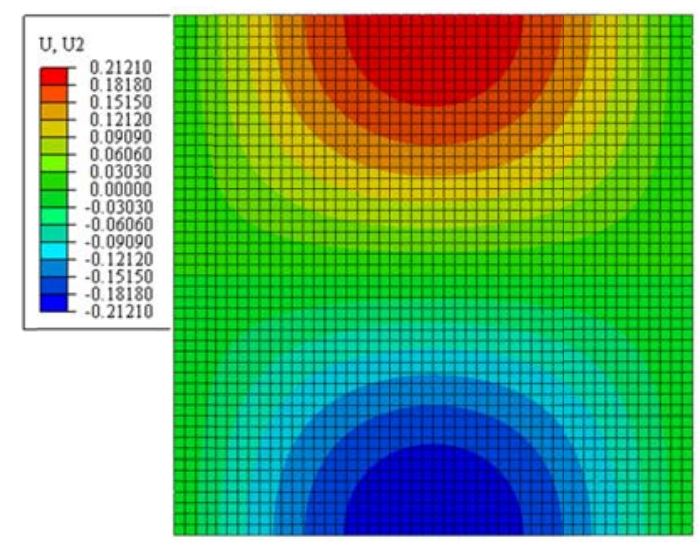

(d)

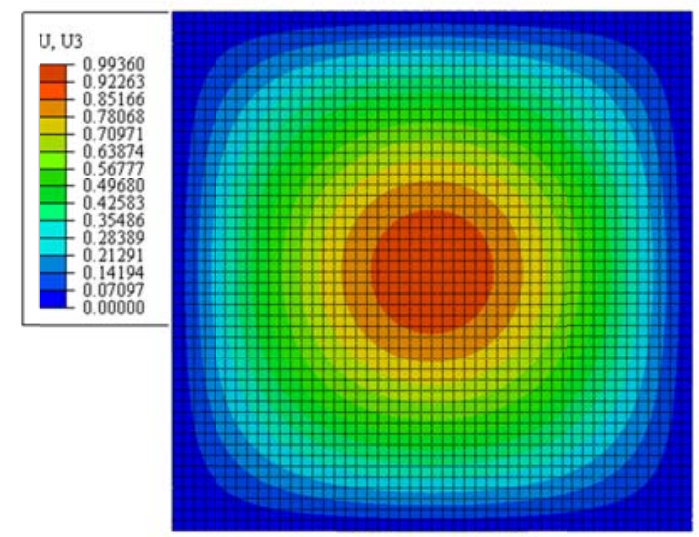

(f)

Fig. 8. Distribution of the in- and out- of plane displacements along $x$ and $y$ at $z=0$. (a), (c) and (e) are the SSA values and (b), (d) and (f) are the corresponding FEM results for $u, v$ and $w(\mathrm{~mm})$, respectively. 


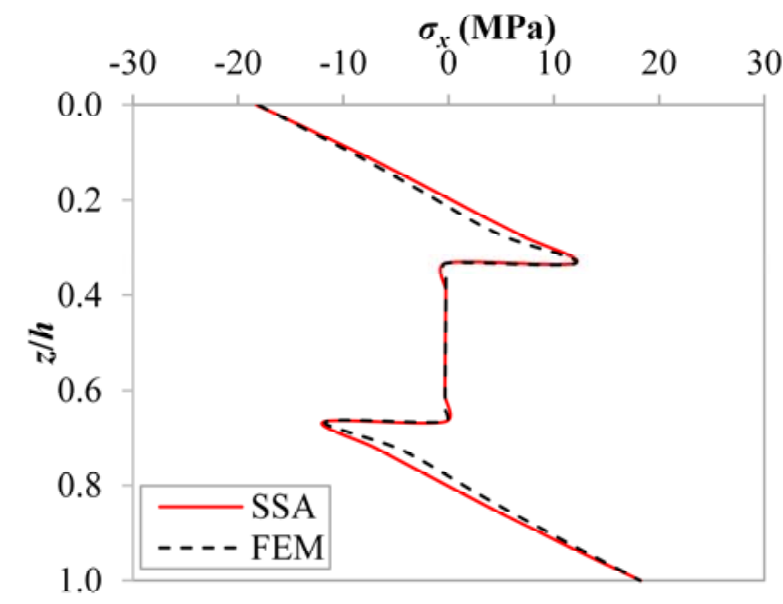

(a)

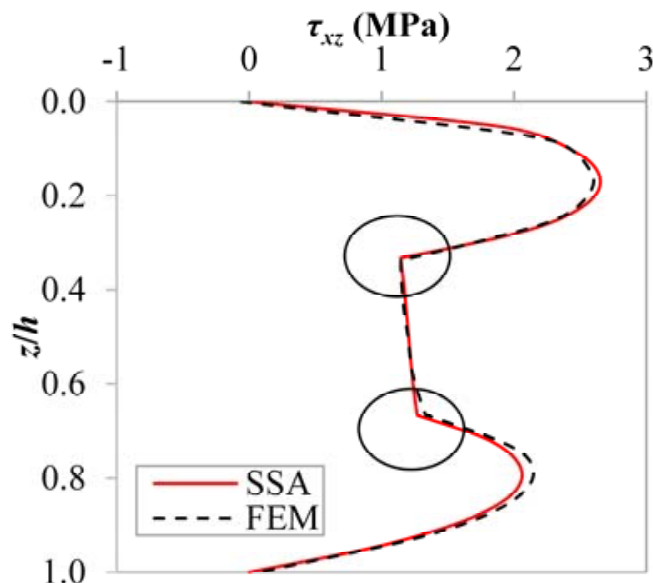

(b)

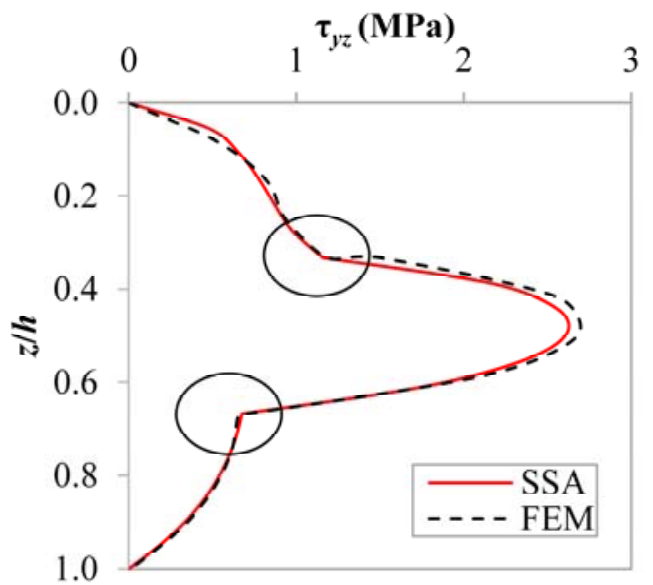

(c)

Fig. 9. SSA and FEM (a) in-plane stress $\sigma_{x}$, (b) transverse shear stresses $\tau_{x z}$ and (c) transverse shear stresses $\tau_{x z}$ stresses through the thickness of the 3-ply CLT panel with $h / a=0.25$.

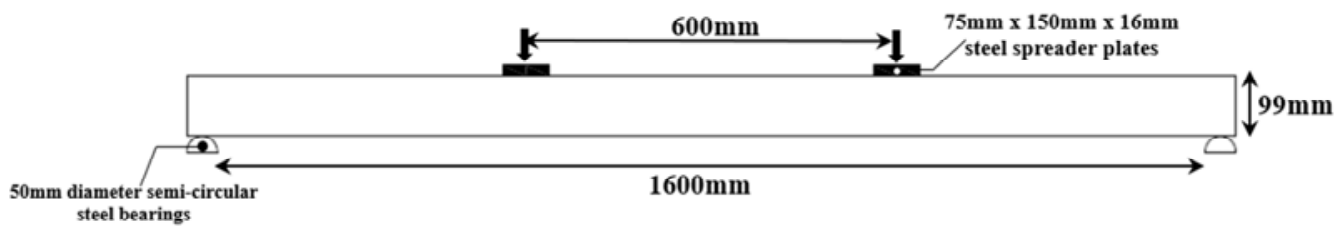

Fig. 10. CLT panel tested by O'Dowd et al. [18]. 


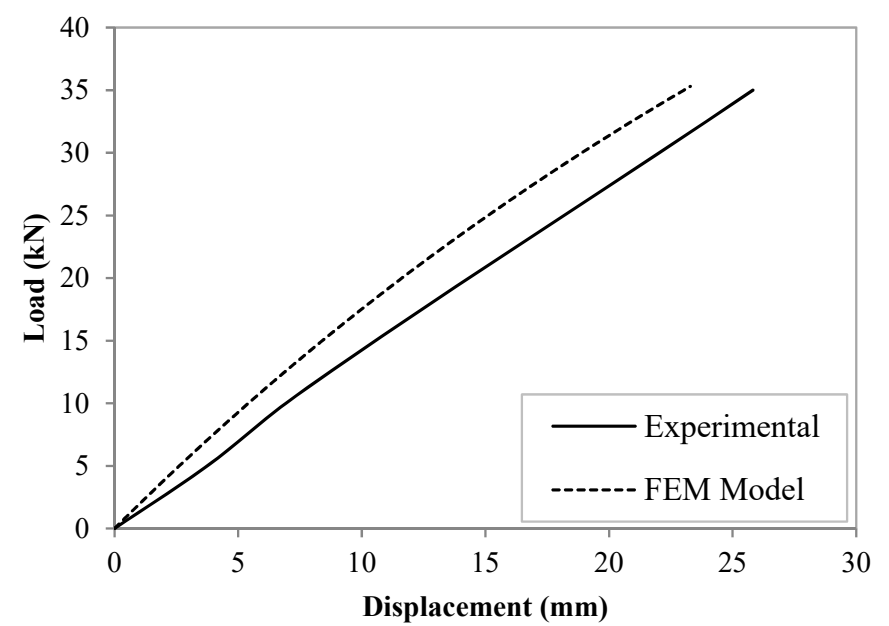

Fig. 11. Case Study 5: Load versus mid-span displacement.

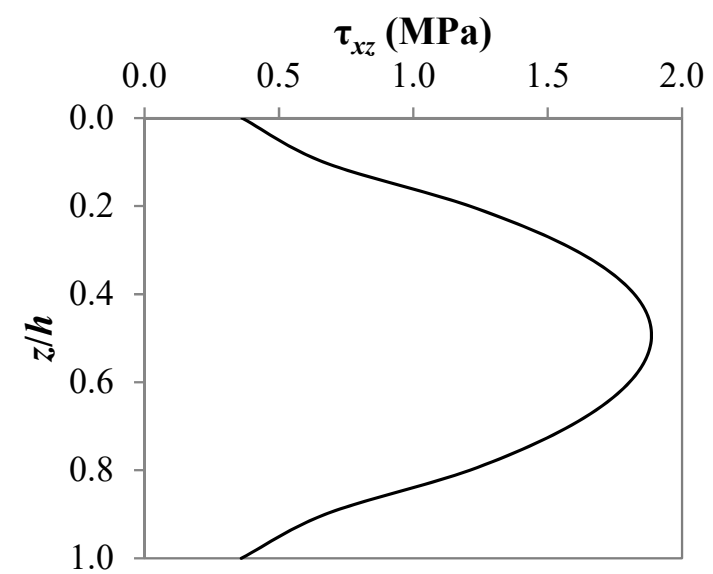

Fig. 12. Case study 5: FEM horizontal shear stress $\left(\tau_{x z}\right)$ through the panel thickness at peak load.

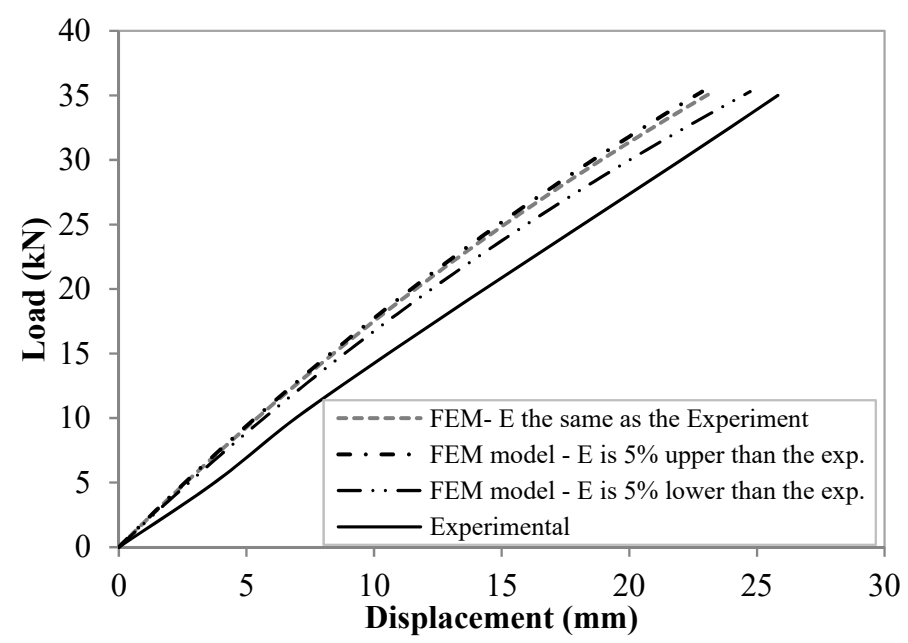

Fig. 13. Case Study 5: Load versus mid-span displacement for the experiment and FEM models with upper and lower $5^{\text {th }}$ percentiles of modulus of elasticity. 
